(c) American Dairy Science Association, 2004.

\title{
Resynchronizing Estrus and Ovulation After Not-Pregnant Diagnosis and Various Ovarian States Including Cysts*
}

\author{
J. S. Stevenson and S. M. Tiffany \\ Department of Animal Sciences and Industry \\ Kansas State University, Manhattan 66506-0201
}

\begin{abstract}
We compared outcomes of 2 protocols used to resynchronize estrus and ovulation in dairy females after a not-pregnant diagnosis. Nulliparous heifers and lactating cows in which artificial insemination (AI) occurred $41 \pm 1 \mathrm{~d}$ earlier were presented every 2 to $3 \mathrm{wk}$ for pregnancy diagnosis by using ultrasonography. Ovaries were scanned, follicles were mapped and sized, presence of corpus luteum was noted, and GnRH was injected ( $\mathrm{d} 0$ ). Females were assigned randomly to receive $\mathrm{PGF}_{2 \alpha} 7 \mathrm{~d}$ later (d 7) and then either received estradiol cypionate (ECP) $24 \mathrm{~h}$ after $\mathrm{PGF}_{2 \alpha}$ (d 8; Heatsynch; $\mathrm{n}=$ 230) or a second GnRH injection $48 \mathrm{~h}$ after $\mathrm{PGF}_{2 \alpha}$ (d 9; Ovsynch; $\mathrm{n}=224$ ). Those detected in estrus since their not-pregnant diagnosis were inseminated, whereas the remainder received a timed AI (TAI) between 65 and $74 \mathrm{~h}$ after $\mathrm{PGF}_{2 \alpha}$. Ovarian scans and blood collected before injections for progesterone analysis were used to classify 4 ovarian status groups: anestrus, follicular cysts, luteal cysts, and cycling, plus an unknown group of females in which no blood sampling or ovarian scans were made. Few females $(5.1 \%)$ were inseminated between not-pregnant diagnosis and $\mathrm{d} 8$. On d 10, more ECP- than GnRH-treated females were inseminated after detected estrus (24 vs. 6\%). Overall, more Ovsynch than Heatsynch females received a TAI (82 vs. $62 \%$ ). Conception rates tended to be greater for females inseminated after estrus (37\%) than after TAI (29\%), particularly for those treated with Heatsynch (41 vs. 27\%) than with Ovsynch (33 vs. 31\%). Those inseminated after estrus conceived $31 \pm 8 \mathrm{~d}$ sooner than those receiving the TAI. Conception rates for females having elevated progesterone $7 \mathrm{~d}$ after the not-pregnant diagnosis were greater than those having low progesterone in Heatsynch $(42 \% ; \mathrm{n}=133$ vs. $25 \% ; \mathrm{n}=55)$ and Ovsynch protocols (33\%; $\mathrm{n}=142$ vs. $15 \% ; \mathrm{n}=45)$, respectively. Conception rates were greater in nulliparous heifers
\end{abstract}

Received June 7, 2004.

Accepted July 20, 2004.

Corresponding author: J. S. Stevenson; e-mail: jss@ksu.edu.

*Contribution Number 04-400-J, from the Kansas Agricultural Experiment Station, Manhattan. than in lactating cows (43 vs. $28 \%$ ) regardless of protocol used. Although overall pregnancy outcomes after a not-pregnant diagnosis were similar in response to either the Ovsynch and Heatsynch protocols, inseminations performed after detected estrus before the scheduled TAI reduced days to eventual conception and tended to increase conception rates, particularly after Heatsynch.

(Key words: synchronized estrus, ovulation, cysts)

Abbreviation key: $\mathbf{C L}=$ corpus luteum, $\mathbf{E C P}=$ estradiol cypionate, Heatsynch $=$ injection of GnRH $7 \mathrm{~d}$ before an injection of $\mathrm{PGF}_{2 \alpha}$, followed in $24 \mathrm{~h}$ by $1 \mathrm{mg}$ of ECP and one fixed-time AI 42 to $50 \mathrm{~h}$ after ECP, Ovsynch $=$ injection of GnRH $7 \mathrm{~d}$ before and $48 \mathrm{~h}$ after an injection of $\mathrm{PGF}_{2 \alpha}$, with one fixed-time $\mathrm{AI}$ at 16 to 22 $\mathrm{h}$ after the second $\mathrm{GnRH}$ injection, $\mathbf{P 4}=$ progesterone, TAI $=$ timed AI.

\section{INTRODUCTION}

Accuracy of early pregnancy detection by ultrasonography exceeds $94 \%$ when diagnoses are made after d 20 (Hanzen and Delsaux, 1987; Boyd et al., 1990). Others have concluded that ultrasonographic diagnosis of pregnancy is practical under field conditions after d 25 (Kahn et al., 1990; Rajamahendran et al., 1994). Routine pregnancy diagnosis is a profitable intervention if detection of nonpregnant cows is made early after AI and if effective measures are taken to increase probability of conception in these cows (Oltenacu et al., 1990). Timing of these measures reduces lost time associated with nonpregnant cows that have prolonged periods before reinsemination.

Earlier identification of nonpregnant females is one way to reduce prolonged interinsemination intervals that occur because of poor efficiency in detecting postinsemination estrus (Stevenson, 2001a). Treating nonpregnant cows with $\mathrm{PGF}_{2 \alpha}$ between 27 and $29 \mathrm{~d}$ after a previous AI induced regression of the corpus luteum (CL) before subsequent insemination after detected estrus or timed AI (TAI), and reduced days to reinsemination and to conception (Stevenson et al., 2003). Other options may include applying various TAI protocols to 
females diagnosed not pregnant. Applying the Ovsynch protocol or substituting estradiol cypionate (ECP) for GnRH in an Ovsynch-like protocol (known as Heatsynch) are viable options. Administering ECP to females in proestrus induced estrus, preovulatory LH surge, ovulation, and normal CL development in dairy heifers (Lopes et al., 2000) and dairy cows (Stevenson et al., 2004). Conception rates of Heatsynchtreated heifers were not different from those in heifers inseminated after detected estrus (Lopes et al., 2000), and those in lactating cows after Heatsynch were similar to those after Ovsynch in 2 experiments (Pancarci et al., 2002).

The objective of the present study was to determine fertility after applying the Ovsynch or Heatsynch protocols to dairy females diagnosed not pregnant by transrectal ultrasonography. An ancillary objective was to determine whether ovarian status at the initiation of the 2 protocols influenced subsequent pregnancy outcomes for either protocol.

\section{MATERIALS AND METHODS}

Lactating Holstein cows ( $\mathrm{n}=414)$ were housed in either tie stalls or free stalls at the Kansas State University Dairy Teaching and Research Center. Replacement Holstein heifers $(n=40)$ were housed in free stalls with an adjacent dirt lot and concrete feed apron behind the feed bunk. Females were presented for pregnancy diagnosis every 2 to 3 wk between August 2000 and November 2002, consisting of 46 separate groups. Days since AI at pregnancy diagnosis averaged $41 \pm 1 \mathrm{~d}$ (range: 27 to 200). Slightly more than $91 \%$ of females were between d 27 and 53 since last AI. Those few females having prolonged intervals since AI were pregnant but aborted and had returned to estrus.

\section{Experimental Design}

Pregnancy status was determined (based on presence of uterine fluid plus a CL and/or detection of embryo) by using transrectal ultrasonography (real time, B-Mode, linear array, diagnostic, ultrasound scanner equipped with a $5-\mathrm{MHz}$ transducer, Aloka 500V, Wallingford, CT). In nonpregnant females, ovaries were scanned, follicles were mapped and sized by using electronic calipers (average of vertical and horizontal measures), and the presence of CL was noted. The following ovarian characteristics were quantified: number of CL, number of follicles $\geq 10 \mathrm{~mm}$ on each ovary and their total per female, diameter of the largest and second-largest follicle (excludes the largest cystic structure[s] in those females bearing cysts), and diameter of all cystic structures (defined later).
After the not-pregnant diagnosis and ovarian examination, all females received i.m. $100 \mu \mathrm{g}$ of $\mathrm{GnRH}$ (d 0; Cystorelin, Merial, Iselin, NJ). Females were then blocked by lactation number ( 1 vs. $2+$ ), and replacement heifers were balanced by BW and age before random assignment to 2 treatments: (1) $25 \mathrm{mg}$ of $\mathrm{PGF}_{2 \alpha}$ (d 7; Lutalyse, Pharmacia Animal Health, Kalamazoo, MI) $7 \mathrm{~d}$ after not-pregnant diagnosis, plus $1 \mathrm{mg}$ of ECP (d 8; ECP, Pharmacia Animal Health, Kalamazoo, MI) 24 $\mathrm{h}$ after $\mathrm{PGF}_{2 \alpha}$ (Heatsynch; $\mathrm{n}=230$ ); or (2) $25 \mathrm{mg}$ of $\mathrm{PGF}_{2 \alpha} 7 \mathrm{~d}$ after not-pregnant diagnosis, plus a second GnRH injection $48 \mathrm{~h}$ after $\mathrm{PGF}_{2 \alpha}(\mathrm{d}$ 9; Ovsynch; $\mathrm{n}=224)$.

To maximize pregnancy outcomes in both treatments, any female detected in estrus after the initial GnRH injection but at least $24 \mathrm{~h}$ before the scheduled TAI was inseminated 8 to $16 \mathrm{~h}$ after first detected estrus (a.m.p.m. rule). Females were observed for estrus at least twice daily (morning and late afternoon), in addition to other casual observations during the work day $(0730$ to $1700 \mathrm{~h}$ ) and while various groups of cows were moved to the milking parlor ( 0530 to $1000 \mathrm{~h}$ and 1730 to 2200 h). In the absence of previous insemination, all remaining females received a TAI at 65 to $74 \mathrm{~h}$ after $\mathrm{PGF}_{2 \alpha}$ (16 to $20 \mathrm{~h}$ after GnRH or 46 to $50 \mathrm{~h}$ after ECP).

Subsequent to treatment inseminations, pregnancy outcome was determined as described previously by using transrectal ultrasonography between 33 and 40 d after AI.

\section{Ovarian Status}

Blood samples were collected from females in 39 of 46 groups ( $83.2 \%$ of females) before the GnRH injection (d 0), before $\mathrm{PGF}_{2 \alpha}(\mathrm{d} 7)$, and $24 \mathrm{~h}$ after $\mathrm{PGF}_{2 \alpha}(\mathrm{d}$ 8) for later radioimmunoassay analysis of blood concentrations of progesterone (P4) in serum (Skaggs et al., 1986). Intra- and interassay CV of 10 assays were 7.6 and $7.5 \%$, respectively.

Ovarian scans and blood collected before injections for P4 analysis were used to classify females into each of 4 ovarian status groups: anestrus, follicular cysts, luteal cysts, and cycling. Females were classified to be anestrus $(n=20)$ when serum concentration of P4 was low $(<1 \mathrm{ng} / \mathrm{mL})$ on $\mathrm{d} 0,7$, and 8 , and few follicles $>10$ $\mathrm{mm}$ were detected on $\mathrm{d} 0$. Females having follicular cysts $(n=12)$ had multiple follicles, including at least one follicle $>20 \mathrm{~mm}$ in diameter, and had low concentrations of P4 on d 0 . Females having luteal cysts $(n=12)$ had multiple follicles including at least one follicle $>20$ $\mathrm{mm}$ in diameter, and had an elevated $(\geq 1 \mathrm{ng} / \mathrm{mL})$ serum concentration of P4 on d 0 . Cycling females $(\mathrm{n}=344) \mathrm{had}$ normal ovarian structures and various combinations of low and/or high concentrations of P4 in blood serum, but none had low serum concentrations of $\mathrm{P} 4$ at all 3 
sampling times. Cycling females were further subdivided into: proestrus ( $\mathrm{P} 4$ was low on $\mathrm{d} 0$, low or high on $\mathrm{d} 7$ or 8 , plus a large follicle $>12 \mathrm{~mm}$ ); metestrus (P4 was low on $\mathrm{d} 0$, high on $\mathrm{d} 7$ or 8 , plus all follicles $<12$ $\mathrm{mm}$ ); early diestrus ( $\mathrm{P} 4$ was high on $\mathrm{d} 0$ and 7 , low or high on d 8, plus a large follicle $>12 \mathrm{~mm}$, and a CL); and late diestrus (P4 was high d 0 , low on $\mathrm{d} 7$ and 8, plus a large follicle $>12 \mathrm{~mm}$, and a CL). Females of unknown ovarian status $(\mathrm{n}=63)$ were those in which ovarian structures were not assessed at pregnancy diagnosis and no blood samples were collected.

\section{Statistical Analyses}

Conception rates were analyzed by using a logistic regression approach (GENMOD; SAS Inst., Inc., Cary, NC) as follows: treatment (Ovsynch vs. Heatsynch); lactation number $(0,1$, and $2+)$; insemination after detected estrus or TAI; interaction of treatment with the preceding factor; number of previous inseminations (covariate); and season $(n=2)$. In subsequent models, ovarian status (cycling [further subdivided into proestrus, metestrus, early diestrus, and late diestrus], anestrus, follicular cyst, luteal cyst, and unknown) was added to the previous model, including an interaction with treatment.

Concentrations of $\mathrm{P} 4$ were analyzed by using a mixedmodels procedure in SAS as follows: ovarian status (anestrus, cycling, follicular cyst, and luteal cyst), lactation number $(\mathrm{n}=3)$, and season $(\mathrm{n}=2)$. In addition, a similar model was applied to detect differences in ovarian status when cycling females were classified further into proestrus, metestrus, early diestrus, and late diestrus.

In all models, differences between Ovsynch and Heatsynch were determined by $F$-tests resulting from ANOVA, whereas all other differences among ovarian status groups were determined by using orthogonal contrasts or the least significant difference test (PDIFF option in SAS), when protected by a significant $(P \leq$ $0.05) F$-test in the ANOVA.

\section{RESULTS}

\section{Insemination Distribution}

Cumulative percentages of all inseminations conducted after detected estrus during $10 \mathrm{~d}$ after not-pregnant diagnosis are illustrated in Figure 1. By d 8 (day of ECP injection), $5.2 \%$ of females preassigned to Heatsynch and $4.9 \%$ preassigned to Ovsynch had been inseminated. On d 9 (day of GnRH injection), another 9.6\% were inseminated in the Heatsynch treatment and another $6.7 \%$ were inseminated in the Ovsynch treatment. Of those inseminated on $d 10$, more $(\mathrm{P}<0.05)$ females were inseminated after detected estrus in the

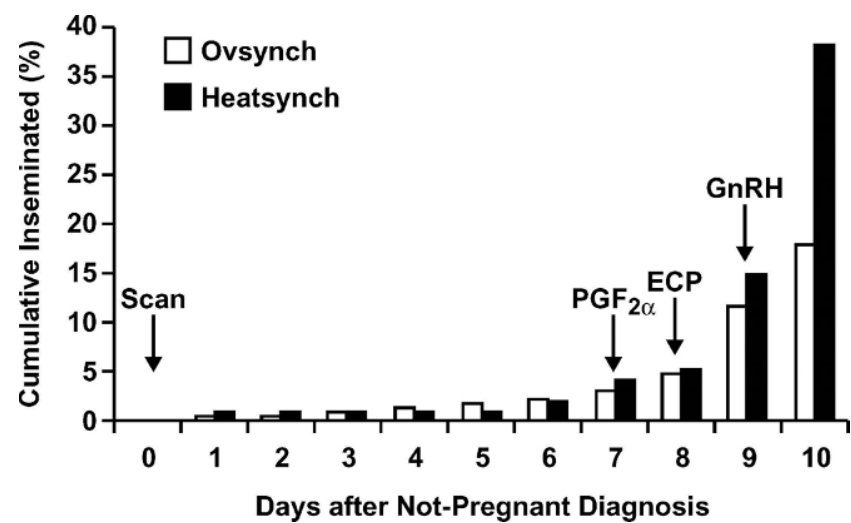

Figure 1. Cumulative percentages of females inseminated after detected estrus during $10 \mathrm{~d}$ after the not-pregnant diagnosis and initiation of treatments as a proportion of all females inseminated. More $(P<0.05)$ females were inseminated after detected estrus on d 10 in the Heatsynch $(23.5 \%$; $\mathrm{n}=54)$ than Ovsynch $(6.3 \%$; $\mathrm{n}=14)$ protocol. Not shown on $\mathrm{d} 10$ are all remaining females that received a timed $\mathrm{AI}$ in the Ovsynch $(82.1 \% ; \mathrm{n}=184)$ and Heatsynch $(61.7 \%$; $\mathrm{n}=142)$ protocols.

Heatsynch $(23.5 \% ; \mathrm{n}=54)$ than in the Ovsynch $(6.3 \%$; $\mathrm{n}=14$ ) protocol. Not shown in Figure 1 are all remaining females that received a TAI on $d 10$. More $(P<0.01)$ Ovsynch $(82.1 \% ; \mathrm{n}=184)$ than Heatsynch $(61.7 \% ; \mathrm{n}=$ 142) females received the TAI.

No differences in conception rates were detected between treatments, when considering all inseminations (Table 1). Replacement heifers had greater $(P<0.05)$ conception rates than lactating cows (Table 1 ). Conception rates also tended $(P<0.10)$ to be greater for females inseminated after detected estrus than for those receiving one TAI ( $37.1 \% ; \mathrm{n}=128$ vs. $28.9 \% ; \mathrm{n}=326)$ in both protocols (Table 1). Conception rates for the 76 females inseminated during $48 \mathrm{~h}$ after ECP were $38.2 \%$ compared with $31 \%$ of the 29 Ovsynch females inseminated during the same period, including those that received GnRH midway during the same 48 -h period. For females inseminated after detected estrus, average days from treatment AI until when conception finally occurred were fewer $(P<0.01)$ than for those receiving the TAI $(45 \pm 10[\mathrm{n}=81]$ vs. $76 \pm 7[\mathrm{n}=174])$.

\section{Ovarian Status}

For females having elevated $(\geq 1 \mathrm{ng} / \mathrm{mL}$ ) concentrations of $\mathrm{P} 47 \mathrm{~d}$ after treatment initiation, regardless of subsequent treatment (Table 1), conception rates were greater $(P<0.001)$ than those having low $\mathrm{P} 4(37.5 \%$; $\mathrm{n}=275$ vs. $20 \% ; \mathrm{n}=100)$. Concentrations of $\mathrm{P} 4$ in females of different ovarian and cycling status are illustrated in Figure 2. Cycling females and those having luteal cysts had greater $(P<0.05)$ concentrations of $\mathrm{P} 4$ on d 0 (day of $\mathrm{GnRH}$ ) than anestrous females and those 
Table 1. Conception rates in dairy females after applying the Ovsynch or Heatsynch protocol.

\begin{tabular}{|c|c|c|}
\hline \multirow[b]{2}{*}{ Item } & \multicolumn{2}{|c|}{ Protocol $^{1}$} \\
\hline & Heatsynch & Ovsynch \\
\hline & - & \\
\hline Overall $^{2}$ & $34.1(230)$ & $31.8(224)$ \\
\hline \multicolumn{3}{|l|}{ Lactation number ${ }^{3}$} \\
\hline 0 & $46.2(20)$ & $40.1(20)$ \\
\hline 1 & $29.5(108)$ & $22.4(92)$ \\
\hline $2+$ & $26.8(102)$ & 32.8 \\
\hline AI after detected estrus ${ }^{4}$ & $41.2(88)$ & $33.0(40)$ \\
\hline Timed AI & $27.1(142)$ & 30.6 \\
\hline \multicolumn{3}{|c|}{ Serum P4 $7 \mathrm{~d}$ after not pregnant diagnosis ${ }^{5}$} \\
\hline High $(\geq 1 \mathrm{ng} / \mathrm{mL})$ & $42.2(133)$ & $32.9(142)$ \\
\hline Low $(<1 \mathrm{ng} / \mathrm{mL})$ & $25.3(55)$ & 14.6 \\
\hline Cycling & $34.8(172)$ & $33.8(174)$ \\
\hline Anestrus & $15.6(13)$ & $16.2(7)$ \\
\hline Follicular cyst & $25.8(6)$ & $38.4(6)$ \\
\hline Luteal cyst & $53.1(6)$ & $28.2(6)$ \\
\hline Unknown & $37.4(33)$ & $24.7(31)$ \\
\hline
\end{tabular}

${ }^{1}$ Heatsynch $=$ injection of GnRH $7 \mathrm{~d}$ before an injection of $\mathrm{PGF}_{2 \alpha}$, followed in $24 \mathrm{~h}$ by $1 \mathrm{mg}$ of estradiol cypionate (ECP) and one fixedtime AI (timed AI) 42 to $50 \mathrm{~h}$ after ECP. Ovsynch = injection of $\mathrm{GnRH}$ $7 \mathrm{~d}$ before and $48 \mathrm{~h}$ after an injection of $\mathrm{PGF}_{2 \alpha}$, with one fixed TAI at 16 to $22 \mathrm{~h}$ after the second $\mathrm{GnRH}$ injection. Adjusted least-squares percentages are illustrated.

${ }^{2}$ Includes all inseminations since treatment initiation on $\mathrm{d} 0$.

${ }^{3}$ Replacement heifers differed $(P<0.05)$ from lactating cows.

${ }^{4}$ Pregnancy rate for AI after detected estrus $(37.1 \% ; \mathrm{n}=128)$ tended $(P<0.10)$ to be greater than that after TAI $(28.9 \% ; \mathrm{n}=326)$.

${ }^{5}$ Females with elevated concentration of progesterone (P4) $7 \mathrm{~d}$ after treatment initiation had greater $(P<0.001)$ pregnancy rates than those with low $\mathrm{P} 4(37.5 \% ; \mathrm{n}=275$ vs. $20 \% ; \mathrm{n}=100)$

bearing follicular cysts. These average differences were maintained on $d 7$, except in those having follicular cysts, in which serum P4 increased to concentrations

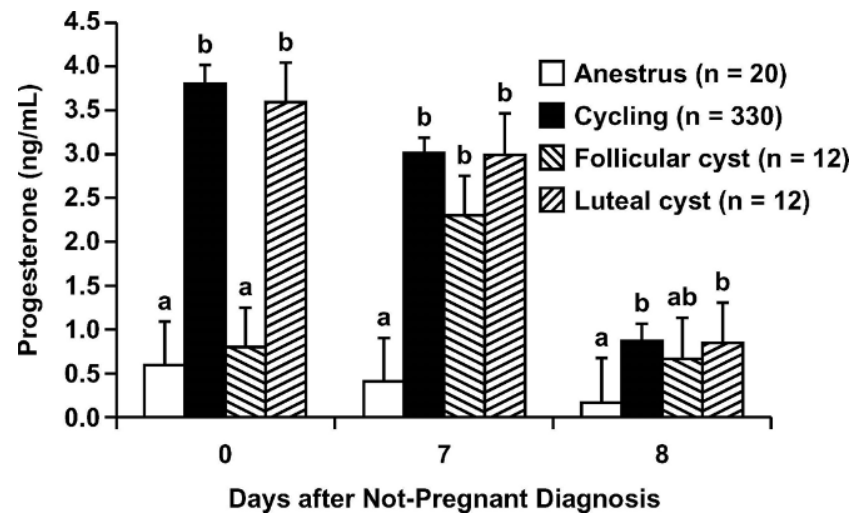

Figure 2. Serum concentrations of progesterone in dairy females classified according to ovarian structures and progesterone status after the not-pregnant diagnosis and initiation of treatments. Injections of $\mathrm{GnRH}$ were administered on $\mathrm{d} 0, \mathrm{PGF}_{2 \alpha}$ on $\mathrm{d} 7$; and estradiol cypionate (ECP) on d 8 (those in the Heatsynch protocol) or $\mathrm{GnRH}$ on d 9 (those in the Ovsynch protocol). Bars within day having different superscript letters differ $(P<0.05)$. similar to those having luteal tissue. In all 12 females having follicular cysts on d 0 (serum $\mathrm{P} 4$ was $<1 \mathrm{ng} / \mathrm{mL}$ ), only 2 failed to have an increase in serum $\mathrm{P} 4 \geq 1 \mathrm{ng} /$ $\mathrm{mL}$ by $7 \mathrm{~d}$ after $\mathrm{GnRH}$ injection. By d 8, $24 \mathrm{~h}$ after $\mathrm{PGF}_{2 \alpha}$, only anestrous females had less $(P<0.05)$ serum P4 than all others.

Conception rates for these females of different ovarian and cycling status are summarized in Table 1. Because of limited numbers of observations in all but the cycling group, potential differences in conception rates were not statistically detectable, but data are presented for informational purposes.

Further investigations of differences in ovarian status of females are summarized in Table 2. Average numbers of CL are shown based on ovarian status. As expected, some CL were detectable in females in proestrus and metestrus, with diestrous females having one or more CL before treatment with GnRH. Concentrations of serum $\mathrm{P} 4$ were reflective of luteal status, with females in late diestrus having the greatest $(P<0.05)$ concentrations, when compared with all other status groups (Table 2). Other females bearing luteal tissue (luteal cysts or those in early diestrus) had greater ( $P$ $<0.05$ ) concentrations of $\mathrm{P} 4$ than all remaining females without luteal tissue.

Fewer total numbers of follicles $\geq 10 \mathrm{~mm}$ in diameter (excluding diameters of the cystic structure[s]) were detected in females having follicular cysts than in females having luteal cysts. Average diameters of the largest cystic structure in females having follicular cysts $(27.1 \pm 1.3 \mathrm{~mm})$ did not differ from those bearing luteal cysts $(28.1 \pm 1.3 \mathrm{~mm})$. Females in proestrus or metestrus had more $(P<0.05)$ follicles than those in diestrus, whereas diameters of the largest (putative dominant follicle) and second-largest follicles did not differ among any of the ovarian status groups.

Eight of the 24 cystic females (only one heifer, which had a follicular cyst; otherwise, 4 follicular and 4 luteal cysts) expressed estrus after not-pregnant diagnosis on the day of TAI, except for one female having a luteal cyst that expressed estrus $1 \mathrm{~d}$ before TAI. Based on our initial classifications of the cystic structure before serum $\mathrm{P} 4$ concentrations were assessed, we identified 3 cows with a luteal cyst and 21 females with follicular cysts. Retrospectively, on the basis of serum P4, we had classified incorrectly 9 of the 21 females having follicular cysts, because each of the 9 had elevated serum $\mathrm{P} 4$ on $\mathrm{d} 0$ and, therefore, had luteal rather than follicular cysts. Concentrations of $\mathrm{P} 4$ on the day of notpregnant diagnosis for females having follicular cysts were less $(P<0.001)$ than those in females bearing luteal cysts $(0.5 \pm 0.5$ vs. $3.3 \pm 0.5 \mathrm{ng} / \mathrm{mL})$.

Conception rates for females within each ovarian status-treatment combination are summarized in Table 2. 
Table 2. Characteristics of ovarian structures at initiation of Heatsynch or Ovsynch protocols. ${ }^{1}$

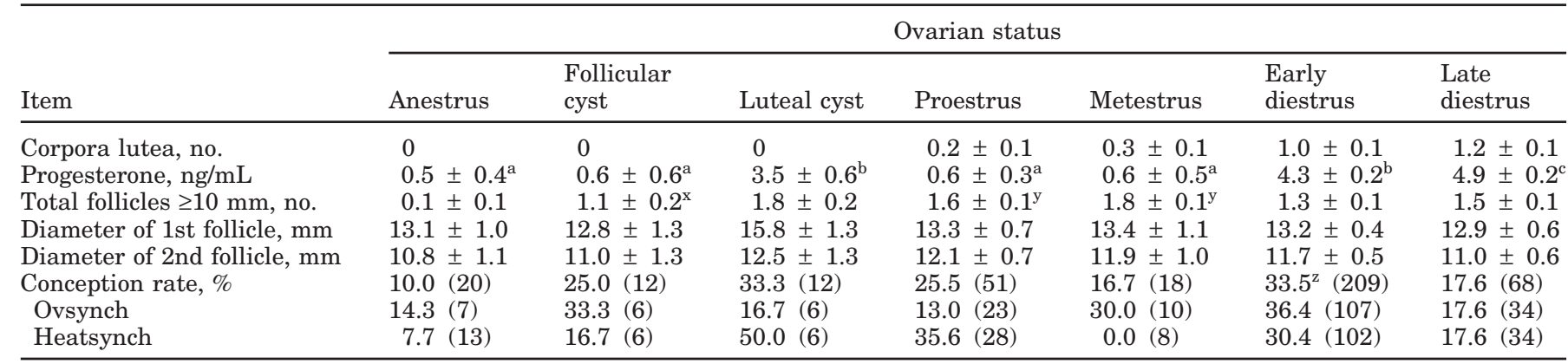

a,b,c Means having different superscript letters differ $(P<0.05)$.

${ }^{x}$ Different $(P<0.05)$ from luteal cysts. These means exclude cystic structures that averaged $27.1 \pm 1.3 \mathrm{~mm}$ in females having follicular cysts and $28.1 \pm 1.3 \mathrm{~mm}$ in females having luteal cysts.

${ }^{\mathrm{y}}$ Females in proestrus and metestrus combined had more $(P<0.05)$ follicles than those in early and late diestrus combined.

${ }^{z}$ Different $(P<0.05)$ from all other groups combined.

${ }^{1}$ Heatsynch = injection of GnRH $7 \mathrm{~d}$ before an injection of $\mathrm{PGF}_{2 \alpha}$, followed in $24 \mathrm{~h}$ by $1 \mathrm{mg}$ of estradiol cypionate (ECP) and one fixedtime AI (timed AI) 42 to $50 \mathrm{~h}$ after ECP. Ovsynch = injection of $\mathrm{GnRH} 7 \mathrm{~d}$ before and $48 \mathrm{~h}$ after an injection of PGF ${ }_{2 \alpha}$, with one fixed TAI at 16 to $22 \mathrm{~h}$ after the second GnRH injection.

When compared with all other females, those in early diestrus at treatment initiation had greater $(P<0.05)$ conception rates $(33.5 \% ; \mathrm{n}=209$ vs. $20.4 \% ; \mathrm{n}=181)$. Other potential differences in conception rates were not statistically detectable because of limited numbers of observations, but results are presented for informational purposes.

\section{DISCUSSION}

We have demonstrated that early pregnancy diagnosis of dairy females via transrectal ultrasonography is a practical means of identifying nonpregnant females for prompt reinsemination, confirming our earlier report (Stevenson et al., 2003). Accuracy of early pregnancy detection by ultrasonography exceeds $94 \%$ when diagnoses are made after d 20 (Hanzen and Delsaux, 1987; Boyd et al., 1990), but accuracy decreases significantly when the position of the uterus is more cranial than caudal to the pelvic outlet (Szenci et al., 1995). Others have concluded that ultrasonographic diagnosis of pregnancy is practical under field conditions after d 25 (Kahn et al., 1990; Rajamahendran et al., 1994).

Routine pregnancy diagnosis is a profitable intervention if detection of nonpregnant cows is made early after $\mathrm{AI}$ and if effective measures are taken to increase probability of conception in these cows (Oltenacu et al., 1990). Timing of these measures reduces lost time associated with nonpregnant cows that have prolonged periods before reinsemination. These prolonged periods were prevented because, regardless of protocol, all nonpregnant cows were reinseminated by $10 \mathrm{~d}$ after notpregnant status was confirmed.

Overall, conception rates did not differ between females assigned to the Heatsynch or Ovsynch protocol, suggesting that both protocols were equally effective in producing pregnancies. In a previous report (Pancarci et al., 2002), in one of 2 experiments, first-lactation cows had greater pregnancy rates than older cows at first service after either Heatsynch or Ovsynch, but the first-lactation cows were inseminated 3 wk later postpartum than the older cows.

Another recent study (Bartolome et al., 2003), in which the Heatsynch or Ovsynch protocol was applied to lactating cows after a not-pregnant diagnosis, reported similar pregnancy rates. Their reported pregnancy rates were less (18\%) than ours, partly because they did not inseminate any female on the basis of estrus, except for those showing estrus on d 9 (day after ECP injection), and inseminations occurred during warmer months in Florida. The insemination distribution in our study indicated that following their procedure would have precluded insemination of $13.2 \%$ of our females inseminated on 1 to 8 in our study. Assuming that all of those females expressing early estrus would not have conceived to the TAI, unadjusted conception rates after Ovsynch (25.9\%) and Heatsynch (25.7\%) would have been reduced only slightly compared with unadjusted conception rates of all females (27.7 vs. $27.4 \%$ ), respectively.

Emphasis of watching for estrus and inseminating those females whose spontaneous estrus and ovulation are not synchronized is critical to maximize the number of pregnancies achieved. Those inseminated after detection of early estrus had greater conception rates, compared with those not detected in estrus, but subsequently received a TAI (46 vs. $25 \%$; DeJarnette et al., 2001). Although more pregnancies tended to occur after inseminations made on the basis of detected estrus than 
after TAI, average days to subsequent conception were reduced by $31 \mathrm{~d}$. This reduction in days to eventual conception confirms greater conception rates for those expressing estrus before AI. It is clear that interventions such as greater emphasis on detecting estrus (Stevenson, 2001b) or early pregnancy diagnosis and subsequent treatment of nonpregnant cows reduce interinsemination intervals and intervals from intervention to conception (Fricke et al., 2003; Stevenson et al., 2003).

Attempts to test for conception differences on the basis of expressed estrus between treatments (ECP vs. $\mathrm{GnRH}$ ) are probably inappropriate because they cannot be assessed easily and are somewhat confounded with timing of either ECP or GnRH injections after $\mathrm{PGF}_{2 \alpha}$. As a result, conceptions after detected estrus for those inseminations conducted on d 9 and 10 (within $48 \mathrm{~h}$ after ECP injection) included mostly females in which estrus was induced by ECP, whereas those inseminated in the Ovsynch protocol on $\mathrm{d} 9$ and 10 include some in which estrus was detected before and after $\mathrm{GnRH}$. Once GnRH is injected, few females show estrus because of GnRH-induced, LH-mediated changes in the preovulatory follicle that preclude further estrogen secretion. The important point is that conception rates are acceptable, whether they resulted from spontaneous estrus or from induced estrus and/or ovulation after either protocol.

Regardless of treatment protocol, only $3.7 \%$ of females were inseminated during $7 \mathrm{~d}$ after $\mathrm{GnRH}$ and not-pregnant diagnosis, compared with $5 \%$ of lactating dairy cows during a similar period after the first $\mathrm{GnRH}$ injection of an Ovsynch-like protocol before first postpartum AI (DeJarnette et al., 2001). In our Ovsynch females, only $11.6 \%$ were inseminated by $48 \mathrm{~h}$ after $\mathrm{PGF}_{2 \alpha}$ (d 0 to 9) compared with $20 \%$ in the former study (DeJarnette et al., 2001). Likewise, as few as $20 \%$ of Ovsynch-treated cows showed estrus after the $\mathrm{PGF}_{2 \alpha}$ injection associated with the Ovsynch protocol (Stevenson et al., 1996). These differences are partly explained by the fact that estrus and/or ovulation in most females assigned to the present study were synchronized previously and were at least $27 \mathrm{~d}$ since last insemination at the onset of treatment. Therefore, our females were likely on $d 7$ or later of an estrous cycle, with many approaching a second potential estrus on the day of notpregnant diagnosis.

Detectable differences in conception rates on the basis of initial ovarian statuses were few. Females in early diestrus at the initiation of either protocol had greater conception rates when compared with those in all other groups. These findings are consistent with those in which cows in early diestrus (Vasconcelos et al., 1999), or those in early diestrus because their estrous cycles were presynchronized (Cartmill et al., 2001; Moreira et al., 2001; El-Zarkouny et al., 2004), had greater pregnancy rates after Ovsynch than those at other stages of the estrous cycle. A preliminary report using these 2 protocols in only lactating cows suggested that those in metestrus and those bearing ovarian cysts had greater odds for pregnancy if the Heatsynch or Ovsynch protocol was applied, respectively (Bartolome et al., 2003).

Conception rates of females diagnosed with cysts were encouraging ( 7 of 24 conceived). Further, the fact that 10 of 12 females bearing follicular cysts had elevated serum concentrations of $\mathrm{P} 4$ by $7 \mathrm{~d}$ after the initial GnRH injection indicated the effectiveness of using GnRH. We do not know, however, which follicular structure luteinized or ovulated (follicular cyst or one or more of the other seemingly normal follicles $\geq 10 \mathrm{~mm}$ in diameter) in response to the injection of $\mathrm{GnRH}$.

Misclassification of females as having follicular cysts, rather than luteal cysts, before assessing serum P4 in blood, is of clinical concern. Applying the inappropriate treatment $(\mathrm{GnRH})$ to those females bearing a luteal cyst would have delayed possible resolution of the cyst under normal circumstances outside the realm of this experiment. Ultrasonographic classification of a luteal cyst was based on visibly detected luteal tissue surrounding the antrum of the cystic structure. Poor resolution with our $5-\mathrm{MHz}$ probe may partly explain these classification errors. Further, some luteal cysts may have been CL that had a large fluid-filled cavity and just seemed abnormal. Because of these classification errors, there may be some merit to injecting cystic females with both $\mathrm{GnRH}$ and $\mathrm{PGF}_{2 \alpha}$ at their diagnosis, and following through $14 \mathrm{~d}$ later with a second dose of $\mathrm{PGF}_{2 \alpha}$, in the absence of previously detected estrus and insemination (Lopez-Gatius and Lopez-Bejar, 2002).

Substituting estrogen for the second GnRH injection in an Ovsynch protocol is a logical choice in the Heatsynch protocol because more cows are detected in estrus after $\mathrm{PGF}_{2 \alpha}$ than after treatment with the standard Ovsynch protocol (Pancarci et al., 2002; Stevenson et al., 2004). In the latter study, of those cows monitored for incidence of ovulation (between 61 and 82 DIM), fewer ovulated after ECP than after GnRH. Intervals from estrus to ovulation and from onset of the LH surge to ovulation, however, were similar after either $\mathrm{GnRH}$ or ECP, suggesting that onset of estrus and the $\mathrm{LH}$ surge are nearly concurrent events after ECP injection.

Cost of an ovulatory dose of estrogen, where market available, is likely to be less than $10 \%$ of the cost of an ovulatory dose of GnRH. Unfortunately, since the present study was completed, ECP was withdrawn from the US market. Other positive benefits of an estrogen, however, include induction of normal estrual characteristics, such as mucous secretion, uterine tone, and re- 
sulting sexual behavior, which are positive indicators of estrus for inseminators and validate the likelihood of estrus (Pancarci et al., 2002).

\section{CONCLUSIONS}

We have demonstrated that early pregnancy diagnosis of dairy females via transrectal ultrasonography is a practical means of identifying nonpregnant females for prompt reinsemination. That process was facilitated by applying either the Ovsynch or Heatsynch protocol after transrectal ultrasonographic diagnosis of no pregnancy. Although overall pregnancy outcomes were similar between protocols, females that expressed estrus and were reinseminated before the scheduled TAI tended to have greater conception rates and did eventually conceive sooner than those receiving the TAI. Unfortunately, the estrogen (ECP) used in the Heatsynch protocol is no longer market available in the US. The concept, however, of applying an early not-pregnant diagnosis, whether it be by transrectal ultrasonography or palpation, and promptly reinseminating, is valid by any means, including using the Ovsynch protocol. When early diagnosis of pregnancy is not possible by ultrasonography, more frequent detection by palpation (e.g., weekly vs. biweekly) on a herd basis reduces the interinsemination interval and increases $\mathrm{AI}$ submission rate. Because AI submission rate is increased, increases in total pregnancy rate should result because submission rate is one of 2 factors that determines overall pregnancy rate (i.e., AI submission rate $\times$ actual conception rate).

\section{ACKNOWLEDGMENTS}

We thank Pharmacia Animal Health (Kalamazoo, MI) for donation of Lutalyse and ECP; Merial (Iselin, NJ), for donation of Cystorelin; Amy Brown, Denise George, and Irene Vanderwerff for assistance in the laboratory; and animal caretakers at Kansas State University Dairy Teaching and Research Center for assistance with cattle.

\section{REFERENCES}

Bartolome, J. A., F. T. Silvestre, A. C. M. Arteche, S. Kamimura, L. F. Archbald, and W. W. Thatcher. 2003. The use of Ovsynch and Heatsynch for resynchronization of cows open at pregnancy diagnosis by ultrasonography. J. Dairy Sci. 85(Suppl. 1):99. (Abstr.)

Boyd, J. S., S. N. Omran, and T. R. Ayliffe. 1990. Evaluation of real time B-mode ultrasound scanning for detecting early pregnancy in cows. Vet. Rec. 127:350-352.

Cartmill, J. A., S. Z. El-Zarkouny, B. A. Hensley, G. C. Lamb, and J. S. Stevenson. 2001. Stage of cycle, incidence and timing of ovulation, and pregnancy rates in dairy cattle after three timed breeding protocols. J. Dairy Sci. 84:1051-1059.
DeJarnette, J. M., R. R. Salverson, and C. E. Marshall. 2001. Incidence of premature estrus in lactating dairy cows and conception rates so standing estrus or fixed-time inseminations after synchronization using $\mathrm{GnRH}$ and $\mathrm{PGF}_{2 \alpha}$. Anim. Reprod. Sci. 67:27-35.

El-Zarkouny, S. Z., J. A. Cartmill, B. A. Hensley, and J. S. Stevenson. 2004. Presynchronization of estrous cycles before Ovsynch and progesterone in dairy cows: Ovulation, pregnancy rates, and embryo survival. J. Dairy Sci. 87:1024-1037.

Fricke, P. M., D. Z. Caraviello, K. A. Weigel, and M. L. Welle. 2003. Fertility of dairy cows after resynchronization of ovulation at three intervals following first timed insemination. J. Dairy Sci. 86:3941-3950.

Hanzen, C., and B. Delsaux. 1987. Use of transrectal B-mode ultrasound imaging in bovine pregnancy diagnosis. Vet. Rec. 21:200-202.

Kahn, W., J. Fraunholz, B. Kaspa, and T. Pyczak. 1990. Sonographic diagnosis of early pregnancy in horses, cattle, sheep, goats, swine, dogs and cats. Standard values and limitations. Berl. Munch. Tierarztl. Wochenschr. 103:206-211.

Lopes, F. L., D. R. Arnold, J. Williams, S. M. Pancarci, M.-J. Thatcher, M. Drost, and W. W. Thatcher. 2000. Use of estradiol cypionate for timed insemination. J. Dairy Sci. 83(Suppl. 1):216. (Abstr.)

Lopez-Gatius, F., and M. Lopez-Bejar. 2002. Reproductive performance of dairy cows with ovarian cysts after different GnRH and cloprostenol treatments. Theriogenology 58:1337-1348.

Moreira, F., C. Orlandi, C. A. Risco, R. Mattos, F. Lopes, and W. W. Thatcher. 2001. Effects of presynchronization and bovine somatotropin on pregnancy rates to a timed artificial insemination protocol in lactating dairy cows. J. Dairy Sci. 84:1646-1659.

Oltenacu, P. A., J. D. Ferguson, and A. J. Lednor. 1990. Economic evaluation of pregnancy diagnosis in dairy cattle: A decision analysis approach. J. Dairy Sci. 73:2826-2831.

Pancarci, S. M., E. R. Jordan, C. A. Risco, M. J. Schouten, F. L. Lopes, F. Moreira, and W. W. Thatcher. 2002. Use of estradiol cypionate in a presynchronized timed artificial insemination program for lactating dairy cattle. J. Dairy Sci. 85:122-131.

Rajamahendran, R., D. J. Ambrose, and B. Burton. 1994. Clinical and research applications of real-time ultrasonography in bovine reproduction: A review. Can. Vet. J. 35:563-572.

Skaggs, C. L., B. V. Able, and J. S. Stevenson. 1986. Pulsatile or continuous infusion of luteinizing hormone-releasing hormone and hormonal concentrations in prepubertal beef heifers. J. Anim. Sci. 62:1034-1048.

Stevenson, J. S. 2001a. Reproductive management of dairy cows in high milk-producing herds. J. Dairy Sci. 84(E. Suppl.):E128E143.

Stevenson, J. S. 2001b. A review of oestrous behaviour and detection in dairy cows. In Fertility in the High Producing Dairy Cow. Occasional pub. no. 26. Brit. Soc. Anim. Sci. 1:43-62.

Stevenson, J. S., J. A. Cartmill, B. A. Hensley, and S. Z. El-Zarkouny. 2003. Conception rates of dairy cows following early not-pregnant diagnosis by ultrasonography and subsequent treatments with shortened Ovsynch protocol. Theriogenology 60:475-483.

Stevenson, J. S., Y. Kobayashi, M. P. Shipka, and K. C. Rauchholz. 1996. Altering conception of dairy cattle by gonadotropin-releasing hormone preceding luteolysis induced by prostaglandin $\mathrm{F}_{2 \alpha}$. J. Dairy Sci. 79:402-410.

Stevenson, J. S., S. M. Tiffany, and M. C. Lucy. 2004. Use of estradiol cypionate as a substitute for $\mathrm{GnRH}$ in an Ovsynch-like protocol for synchronization of ovulation in dairy cattle. J. Dairy Sci. 87:3298-3305.

Szenci, O., G. Gyulai, P. Nagy, L. Kovacs, J. Varga, and M. A. Taverne. 1995. Effect of uterus position relative to the pelvic inlet on the accuracy of early bovine pregnancy diagnosis by means of ultrasonography. Vet. Q. 17:37-39.

Vasconcelos, J. L. M., R. W. Silcox, G. J. Rosa, J. R. Pursley, and M. C. Wiltbank. 1999. Synchronization rate, size of the ovulatory follicle, and pregnancy rate after synchronization of ovulation beginning on different days of the estrous cycle in lactating dairy cows. Theriogenology 52:1067-1078. 